\title{
Is there a low-risk anomaly across countries?
}

\author{
Adam Zaremba ${ }^{1}$
}

Received: 13 June 2015/Revised: 31 August 2015/Accepted: 1 September 2015/

Published online: 21 September 2015

(C) The Author(s) 2015. This article is published with open access at Springerlink.com

\begin{abstract}
The aim of this paper is to examine the parallels between the countrylevel and the stock-level low-risk anomalies. The inter-market variation in returns do not follow the intra-market patterns. Country-level returns are positively related to standard deviation, value at risk, and idiosyncratic volatility, although the effect is largely explained by cross-national value, size and momentum effects. The riskreturn relationship seems to be stronger in the cases idiosyncratic risk and is almost non-existent in the case of systematic risk (market beta). Furthermore, additional sorting on value at risk may markedly improve the performance of size and value strategies at the country level. The investigations are based on the cross-section analysis of 78 national stock markets for the period 1999-2014.
\end{abstract}

Keywords Low risk anomaly - Beta $\cdot$ Standard deviation · Value at risk · Idiosyncratic volatility · Inter-market effects - Cross-section of returns · Factor returns · International diversification · Country selection strategies · Factor investing

JEL Classification $\mathrm{G} 11 \cdot \mathrm{G} 12 \cdot \mathrm{G} 15$

\section{Introduction}

This paper is aimed at examining the low-risk anomaly at the country level. Low risk anomaly is a concept arising from the stock-level cross-sectional studies, which is related to one of the most profound questions in the financial literature, namely: Are safe stocks better investments than risky ones? The crucial assumption of the

Adam Zaremba

adam.zaremba@ue.poznan.pl;

http://adamzaremba.pl/

1 Poznan University of Economics, al. Niepodleglosci 10, 61-875 Poznan, Poland 
capital asset pricing model (CAPM) of Sharpe (1964), Lintner (1965) and Black (1972) is the existence of a positive linear relationship between the systematic stock market risk measured with their betas and the expected returns. This relationship has been generally confirmed by the initial tests of the U.S. stock market (Black et al. 1972; Fama and MacBeth 1973; Blume 1970; Miller and Scholes 1972; Blume and Friend 1973). The CAPM is built on the modern portfolio theory, according to which investors diversify risk by holding a portfolio of stocks. However, for various reasons, such portfolios are often poorly diversified (Goetzman and Kumar 2008). By assuming the phenomenon of the under-diversification, some theories indicate that also the idiosyncratic risk should be positively correlated with the expected returns in the cross-section analysis (Levy 1978; Merton 1987; Malkiel and Xu 2004). Papers of West and Tinic (1986), and Fu (2009) support the theoretical models and provide empirical evidence that portfolios with higher idiosyncratic volatility yield higher average returns. As the systematic and idiosyncratic risks sum up to the total volatility, this parameter should also be positively correlated with returns. Indeed, there are several studies which seem to confirm this assumption by showing that risk measures related to the total variability are positively correlated with the expected returns. For example, Bali and Cakici (2004) find that there is a strong positive relationship between the average returns and value at risk, which is robust against different investment horizons and various levels of loss probability. Chen et al. (2014) confirm this observation in the emerging stock market in Taiwan. In addition, Ang et al. (2006a) focus on the downside risk and show that the crosssection analysis of stock returns reflects a significant downside risk premium.

Surprisingly, the results of many papers seem to be entirely contrary to the above-described theories. This phenomenon-called a "low-risk anomaly" (Ang 2014) - is a combination of three effects, where the third one is the consequence of the first two effects:

1. Volatility is negatively related to future returns.

2. Realized beta is negatively related to future returns.

3. Minimum variance portfolios outperform the market.

There is mounting evidence of the anomaly which follows from many studies conducted over the last forty years, since its first discovery in early '70s. In their paper of 1970, Friend and Blume examined the stock returns for the period 1960-1968 with the use of the CAPM beta and volatility, drawing a conclusion that "risk-adjusted performance is dependent on risk. The relationship is inverse and highly significant" (Friend and Blume 1970). Shortly afterwards, this observation was confirmed by Haugen and Heins (1975) who analysed the U.S. stock market in the period between 1926 and 1971, reaching the conclusion that "over the long run, stock portfolios with lesser variance in monthly returns have experienced greater average returns than their 'riskier' counterparts" (Haugen and Heins 1975). It also appears that market beta is far from being the ideal predictor of stock returns. The first challenge has been probably described in the paper of Jensen et al. (1972) who argue that, despite the positive relation between beta and returns, the correlation is probably "too flat" compared to the CAPM predictions. This results in the abnormal 
returns on low-beta stocks. Finally, the relevance of the CAPM was undermined in the influential paper of Fama and French (1992) which proves that "beta shows no power to explain average returns" (Fama and French 1992) when considering the size and value effects. These studies led to the proliferation of further research studies providing the evidence for the low-risk anomaly in the U.S. stock market (Baker and Haugen 1991; Chan et al. 1999; Jagannathan and Ma 2003; Clarke et al. 2006; Ang et al. 2006b; Baker et al. 2011) and in other global equity markets (Blitz and van Vliet 2007; Ang et al. 2008; Baker and Haugen 2012; Blitz et al. 2013).

Furthermore, in recent studies, new asset pricing factors have been introduced based on the risk anomaly. Frazzini and Pedersen (2014) propose a betting-againstbeta (BAB) factor which refers to the returns on the leveraged portfolio of low-beta stocks hedged with high-beta stocks. Ang (2014), p. 339 constructs a volatility factor which, despite similar design, is based on the standard deviation instead of the market beta. The above-mentioned factors have not only delivered long-term positive abnormal returns, but also managed to explain the alphas of Warren Buffet's investment portfolio (Frazzini et al. 2013).

Low-risk anomaly seems to be so astonishingly simple and powerful that Robin Greenwood, professor at Harvard Business School, called it "the Mother of all inefficiencies" (Ang 2014, p. 332) in 2010. Nevertheless, the grounds for its existence are still a mystery to a large extent. Several possible explanations are found in the financial literature. According to some papers, the reasons are data mining issues and the sensitivity of the resulting illiquidity effects and portfolio weighting methods (Bali and Cakici 2008; Han and Lesmond 2011). However, the best counterargument is probably the pervasiveness of this anomaly. The low-risk effect has been observed in international stocks, sovereign and corporate bonds, credit derivatives, currencies (Frazzini and Pedersen 2014), and even commodities (Blitz and de Groot 2014) or option markets (Cao and Han 2013). Frazzini and Pedersen (2014) attempt to explain the beta anomaly with leverage constraints, arguing that investors who are not able to borrow money create excessive demand for high-beta stocks. However, the leverage constraints explain only the low returns of risky stocks, whereas the abnormal positive returns of safe stocks remain unexplained (Ang 2014, p. 342). Ang (2014), pp. 342-343 blames the agency problems for the risk anomaly and suggests that institutional investors have to stick to the benchmark and, therefore, are unable to take bets on extreme-beta stocks characterized with significant tracking error. Furthermore, several studies suggest that the under-pricing of safe stocks and over-pricing of risky stocks may simply result from the investors' preferences regarding the trade environment (Boyer et al. 2010; Bali et al. 2011; Ilmanen 2012). Finally Hou and Loh (2014) conduct a comprehensive analysis of numerous explanations, proving that even taken together as groups they are not able to explain more than half of all the anomalies.

Previous studies on the low-risk anomaly concentrated solely on the stock-level effects. However, several questions remained unanswered, namely: Do any parallels occur the country level? Is the risk also a valid determinant of a cross-national variation in stock returns? In an attempt to answer these questions, this study aims to endow the low-risk investing with a new global dimension. 
The concept of finding parallels between stock-level and country-level crosssectional return patterns has its precedence in a number of previous studies on the cross-national value, momentum and size effects. First, Macedo (1995), Asness et al. (1997), Kim (2012), Zaremba (2015a) claim that stock markets with low fundamental indicators, for example $\mathrm{P} / \mathrm{E}$ ratio, yield higher returns than markets with high ratios. Second, Richards (1997), Bhojraj and Swaminathan (2006), Balvers and Wu (2006) and Blitz and van Vliet (2008) argue that top performing markets tend to continue to outperform the market, while 'laggard countries' retain their negative momentum. Third, Keppler and Traub (1993) and Keppler and Encinosa (2011) conclude their papers by saying that 'small is beautiful'. According to them, the portfolios composed of small capitalization markets deliver higher returns than big markets in a long run. The additional evidence on the described phenomena is provided by Desrosiers et al. (2004), Asness et al. (2013), and Angelidis and Tessaromatis (2014). Finally, Zaremba (2015b) proves that certain parallels between country-level and stock-level quality effects are also observable across the data.

This paper aims to comprehensively investigate the country-level risk effects. The study contributes to the financial literature in two ways. First, it examines and compares performance portfolios from sorts on the range of risk indicators. The calculations are based on a broad sample of 78 single country stock markets for the period 1999-2014. Second, inspired by similar observations from the stock-level studies (Novy-Marx 2013), the paper examines whether additional sorting on the risk may improve the performance of value and size strategies at the country level.

The basic motivation to conduct this study were structural changes which have taken place in the international equity markets in recent decades. The increased integration and openness of global financial markets led to the rise in correlations between stock market returns in various countries (Bekaert and Harvey 2000; Quinn and Voth 2008). As a result, the diversification benefits of international investments have fallen markedly, and the cross-country correlations keep growing (Authers 2010). ${ }^{1}$ The disappearance of diversification opportunities has significant impact on the market practitioners. This trend indicates the growing importance of country selection strategies as part of the investment process (Hester 2013).

The described phenomenon is associated with the proliferation of passive investment products which ensure investors easy access to international markets (and it might have been fuelled by their emergence). Futures markets, index funds and exchange traded funds (ETFs) offer investors liquid and cheap investment opportunities in the global markets. Investment Company Institute (2014) reports that over 430 billion dollars were invested in 490 international equity ETFs in the USA, in September 2014. What is more, EY expects the global ETF market to rise 15-30 \% annually over the forthcoming years (EY 2014).

Compared to the abundant opportunities and the size of the global ETF market, investment tools available for ETF investors seem to be still astonishingly modest. The stock-level investors have at their disposal ample literature dealing with cross-

\footnotetext{
1 Numerous studies document that the financial contagion could be now easily spread even into emerging and frontier markets, e.g., Dornbusch et al. (2000), Scott (2014), Tanai and Lin (2013), Le and David (2014).
} 
sectional and time-series patterns, as well as asset pricing models. Such tools still need to be developed in the field of passive ETFs and index products. One of the overarching aims of this paper is to fill this gap, at least partially.

Key findings of the study may be summarized as follows. First, there is no evidence for the country-level low-risk anomaly observed. Returns are positively correlated with the value at risk, standard deviation and idiosyncratic volatility, although it is largely explained by cross-national value, size and momentum effects. Second, the relationship seems to be stronger in the case of idiosyncratic risk measures and is almost non-existent in the case of the systematic risk (market beta). Third, additional sorting on value at risk may markedly improve the performance of size and value strategies at the country level.

The primary source of the data at the country-level is Bloomberg. The sample period covers the years between 1999 and 2014. In terms of asset pricing tests, the study attempts to explain the returns on the portfolios sorted on risk. The returns are evaluated by means of the country-level cross-sectional pricing models.

The structure of the further part of this papers is as follows. Section 2 describes research methods and data sources. Section 3 presents the findings of the study and Sect. 4 concludes the paper.

\section{Methodology and empirical data}

The paper examines three hypotheses. First, it is analysed whether risk is a valid determinant of cross-sectional variation in returns on country indices. The focus is placed on four distinct risk indicators: market beta, standard deviation, value at risk and idiosyncratic variance. Second, it is investigated whether risk effects are equally strong across various size and B/M classes of countries. In other words, the third question is whether it is possible to improve cross-national value and size strategies with additional sorts on risk. Thus, single- and double-sorted capitalizationweighted portfolios were built from the sorts on characteristics of equity indices and their performance was evaluated with multifactor asset pricing models.

\subsection{Playing field}

This research is based on the returns on international stock market indices and the accounting data obtained from Bloomberg. Monthly time-series are implemented as they provide the sufficient number of observations (188) to ensure the reliability of the conducted tests and allow for the avoidance of excessive exposure to micro-structure issues (de Moor and Sercu 2013). For all the examined countries, MSCI indices are used to maintain the consistent methodology for the computation of returns across all the analysed countries. MSCI indices are widely tracked capitalization-weighted global equity benchmarks which additionally serve as the basis for numerous futures contracts and over 650 exchanged traded funds (ETFs) throughout the world. ${ }^{2}$ Thus, the selection of

\footnotetext{
${ }^{2}$ Data from http://www.msci.com/products/indexes/ [accessed 1 November 2014].
} 
MSCI is also aimed at aligning this research with investment practice, as these indices are constructed and managed with a view to being fully investable from the perspective of international institutional investor (MSCI 2014a) and cover approx. $85 \%$ of all stock market capitalizations in countries which they represent (MSCI 2014b). If a MSCI index is not available for a given country, the second choice is Dow Jones, and the third choice is STOXX. The detailed list of all countries investigated in this paper along with their corresponding indices is attached in form of the "Appendix". 3

Returns are computed based on the capitalization-weighted gross total return indices, which means that they are adjusted according to corporate actions (splits, reverse splits, issuance rights, etc.) and cash distributions to investors (dividends). The sample period for returns is February 1999 to September 2014, if available. The total sample includes 78 country equity markets and, according to the author's best knowledge, this is one of the broadest samples examined in studies of this kind. Both existing and discontinued indices (for example MSCI Venezuela) are used to avoid the survivorship bias. A stock market is included in the sample in a month $t$ if it is possible to compute its size, value and momentum indicators at the end of month $t-1$ and its returns in month $t$. The size of the sample increases along with the development of global capital market which has taken place in recent years and the time series average is 56 .

The country-level parallels between the size, value, and momentum variables at the stock level are calculated as follows. Size means the total stock market capitalization of a given equity index. As a result, it provides a good approximation of the full country equity market as the MSCI indices always cover approx. $85 \%$ of the total country capitalization. This approach towards the size measurements follows from the theoretical and empirical evidence provided by Asness et al. (1997), Keppler and Traub (1993), Keppler and Encinosa (2011), and Zaremba (2015a). Book-to-market ratio of an index portfolio is value-related variable, which is weighted according to the methodology of a given index. To avoid the look-ahead bias, the ratios based on the accounting data are lagged 3 months. Finally, in the case of the momentum metric, we closely follow the approach presented by Asness et al. (2013) and Zaremba (2015a), which means that the momentum in month $t$ is calculated as cumulative gross returns in months $t-12$ to $t-1$.

Initial market and accounting data is collected in local currencies, however, I agree with Liew and Vassalou (2000), and Bali et al. (2013), that comparisons using different currency units could be misleading. This is especially true in emerging and frontier markets, where inflation and risk-free rates are sometimes very high and differ significantly across markets. Therefore, I follow the approach of Bekaert et al. (2007), Brown et al. (2008) or Liu et al. (2011), and denominate all data in USD to obtain polled international results. In order to be consistent with the USD approach, excess returns are computed over the one-month Libor rate.

\footnotetext{
${ }^{3}$ For the brevity we do not report the detailed statistics on this dataset. They could be found in the study of Zaremba (2015a).
} 


\subsection{Examined portfolios}

This papers investigates the performance of returns on various risk portfolios. Thus, in each month $t-1$, all stock market indices are ranked against their risk characteristics. Four distinct risk proxies are used: beta, standard deviation, value at risk, and idiosyncratic volatility. Beta is the regression coefficient of returns on the examined portfolio to the returns on the capitalization-weighted portfolio for all the countries in the sample. Standard deviation is a simple standard deviation of returns. Value at risk is measured as the empirical 5th percentile of historical observations. Idiosyncratic volatility is a variance of the given index unexplained by the regression of its returns to the returns on the global portfolio. I use 12-24 months horizon (as available) to estimate the risk proxies. All computations were based on monthly time-series. Next, five subgroups are formed. For each characteristic, the 20th, 40th, 60th and 80th percentiles are defined as breakpoints and, thus, five subgroups are obtained. Finally, the indices in the respective groups are value weighted to form portfolios.

The value weighting scheme is chosen intentionally in order to avoid the impact of returns on rebalancing (Willenbrock 2011). Their influence may be particularly distorting in the case of this research, as the level of returns is related to the volatility of portfolio constituents (Erb and Harvey 2006). By opting for the capitalization-weighting scheme, the paper tries to isolate this effect. Nevertheless, the limitation of this approach is the possible excessive influence of the biggest equity markets. Besides, it seems rational to assume that, with the use of liquid futures or ETFs, investors are able to attain easily either equal or capitalizationbased exposures to the international markets. Finally, some authors (for example Bali and Cakici 2008) find that the anomalies related to price risk are predominantly distinctive for capitalization-weighted portfolios.

In most cases, the performance of zero-cost portfolios based on risk variables is also presented. There are basically long/short portfolios which are $100 \%$ long in the most risky quintile and $100 \%$ short in the safest quintile.

This study also investigates whether the risk effects are equally strong across various size and $\mathrm{B} / \mathrm{M}$ classes of stock markets (i.e. in big, medium and small markets). To this end, I form double-sorted portfolios from stock market indices sorted on the size or $\mathrm{B} / \mathrm{M}$ indicators and risk. At the end of each month $t-1$, all indices are sorted on their risk and $\mathrm{B} / \mathrm{M}$ or size. I define 30th and 70th percentiles as the risk and $\mathrm{B} / \mathrm{M}$ or size breakpoints. The intersection of the independent $3 \times 3$ sorts on risk and size or B/M gives nine portfolios. Finally, I weight the sorts with value to obtain double-sorted portfolios which are evaluated in a similar fashion to single-sorted portfolios.

\subsection{Performance evaluation and asset pricing models}

The examination of multi-country international portfolios requires the use of an appropriate asset pricing model, which is consistent with the perspective of an international investor implementing a top-down country-level selection strategy, who builds portfolios composed of ETFs or futures rather than single stocks. Thus, 
this paper applies the alternative method of computation of asset pricing factors which is based on the country-level data.

This research analyses the portfolios against two distinct asset pricing models estimated from the cross-national data. They are basically new modifications of the existing, well-documented and broadly-employed models. The first one is the classical Capital Asset Pricing Model (Sharpe 1964). The model assumes that asset returns depend only on the market portfolio. The second model is the four-factor model which was originally introduced by Carhart (1997) and it is the expansion of the three-factor model of Fama and French (1993). It additionally accounts for size, value and momentum effects, which are represented by SMB, HML and WML portfolios. SMB (small minus big) is the difference in returns on diversified portfolios of small and large caps, HML (high minus low) is, in general, the difference in returns on portfolios of diversified value (high $\mathrm{B} / \mathrm{V}$ ) and growth (low $\mathrm{B} / \mathrm{V}$ ) stocks, while WML (winners minus losers) means the difference between returns on diversified portfolios of countries with the highest and the lowest returns over the previous year. The detailed description of the country-level models employed in this paper is presented in a study of Zaremba (2015a).

All the regression models are estimated using the OLS regressions and tested in a parametric manner. The models are used to assess the performance of single- and double-sorted portfolios, which are described in detail in the data section. It is examined whether the application of a model to a certain portfolio leaves a statistically significant intercept unexplained. In order to find whether the intercepts in a group of portfolios are statistically different from zero, they are evaluated with the GRS test statistic, as suggested by Gibbons et al. (1989).

\section{Results and discussion}

First of all, this section presents the performance of the portfolios from the single sorts on risk. Next, it describes the interactions between the value, size and risk effects at the country level.

\subsection{Performance of portfolios from single sorts}

Table 1 presents the basic statistics of the risk-sorted portfolios. It seems that market beta, which is the key element of the neoclassical assert pricing theory, has the poorest relation to the expected returns of all examined characteristics.

Not only is the beta-return relationship is non-linear, but also it is not even monotonic. The return on long/short portfolio, which is long for the high-beta countries and short for the low-beta countries, has the mean monthly return of $0.52 \%$ (not statistically different from zero). The top-beta countries have also the highest standard deviation.

The portfolios sorted on standard deviation, value at risk and idiosyncratic volatility reveal some similarities. In all three cases, the returns are almost monotonic which means that portfolios with the lowest risk have the lowest excess returns, whereas the highest risk coincides with the highest returns. For example, 
Table 1 Excess returns on quintile portfolios sorted on risk

\begin{tabular}{|c|c|c|c|c|c|c|}
\hline & Bottom & 2 & 3 & 4 & Top & $\mathrm{T}-\mathrm{B}$ \\
\hline \multicolumn{7}{|l|}{ Beta } \\
\hline Mean & $0.17(0.45)$ & $0.44(1.30)$ & $0.38(0.96)$ & $0.71(1.62)$ & $0.68(1.22)$ & $0.52(1.21)$ \\
\hline Standard dev. & 5.09 & 4.66 & 5.42 & 5.96 & 7.66 & 5.82 \\
\hline Sharpe ratio & 0.03 & 0.09 & 0.07 & 0.12 & 0.09 & 0.09 \\
\hline Mean market cap. & 384 & 707 & 917 & 482 & 220 & \\
\hline \multicolumn{7}{|l|}{ Standard deviation } \\
\hline Mean & $0.26(0.81)$ & $0.24(0.58)$ & $0.55(1.19)$ & $0.70(1.25)$ & $1.05(1.83)$ & $0.79(2.10)$ \\
\hline Standard dev. & 4.39 & 5.68 & 6.25 & 7.65 & 7.83 & 5.12 \\
\hline Sharpe ratio & 0.06 & 0.04 & 0.09 & 0.09 & 0.13 & 0.15 \\
\hline Mean market cap. & 1564 & 563 & 253 & 175 & 105 & \\
\hline \multicolumn{7}{|l|}{ Value at risk } \\
\hline Mean & $0.19(0.56)$ & $0.40(1.00)$ & $0.83(1.82)$ & $0.41(0.79)$ & $0.94(1.64)$ & $0.75(2.02)$ \\
\hline Standard dev. & 4.60 & 5.45 & 6.23 & 7.08 & 7.82 & 5.09 \\
\hline Sharpe ratio & 0.04 & 0.07 & 0.13 & 0.06 & 0.12 & 0.15 \\
\hline Mean market cap. & 1308 & 588 & 329 & 331 & 114 & \\
\hline \multicolumn{7}{|c|}{ Idiosyncratic volatility } \\
\hline Mean & $0.26(0.80)$ & $0.25(0.61)$ & $0.54(1.17)$ & $0.62(1.11)$ & $1.07(1.86)$ & $0.81(2.16)$ \\
\hline Standard dev. & 4.39 & 5.65 & 6.23 & 7.67 & 7.83 & 5.11 \\
\hline Sharpe ratio & 0.06 & 0.04 & 0.09 & 0.08 & 0.14 & 0.16 \\
\hline Mean market cap. & 1564 & 560 & 253 & 176 & 108 & \\
\hline
\end{tabular}

The table reports means, standard deviations, and Sharpe ratios of excess returns on quintile portfolios sorted on four distinct risk indicators: beta, standard deviation, value at risk and idiosyncratic volatility. "Bottom" always denotes countries with the lowest risk and "top" with the highest risk. "T-B" is a zerocost portfolio, which is long the bottom countries and short in the top countries. The means and standard deviations are expressed in percent, while market capitalizations are in billion US dollars

countries with the bottom idiosyncratic volatility have mean monthly excess returns of $0.26 \%$, while markets with the top idiosyncratic volatility earn on average $1.07 \%$. The returns on long/short portfolios vary from 0.75 to $0.81 \%$ and are significantly different from zero. The higher returns are associated with higher risk in terms of standard deviation.

The scale of cross-sectional variations is fairly large, at least compared to other country-level cross-sectional patterns. For example, Zaremba (2015a) analyses the performance of a number of long/short portfolios based on various value, size and momentum indicators, but neither of them has excess returns as high as the long/ short portfolios based on the $\mathrm{VaR}$, total and idiosyncratic volatility. The differences in performance between top and bottom quintiles, however, are slightly lower than in the case of similar portfolios estimated based on the stock-level data, for instance in papers of Bali and Cakici (2004, 2008) or Ang et al. (2006b).

The examination of the risk-sorted portfolios with the use of CAPM and fourfactor model provides some additional insights (Table 2). First, the outcomes reveal no parallels to the cross-sectional observations of low-beta anomaly discovered by Frazzini and Pedersen (2014) or low-volatility effect described by Ang (2014). 


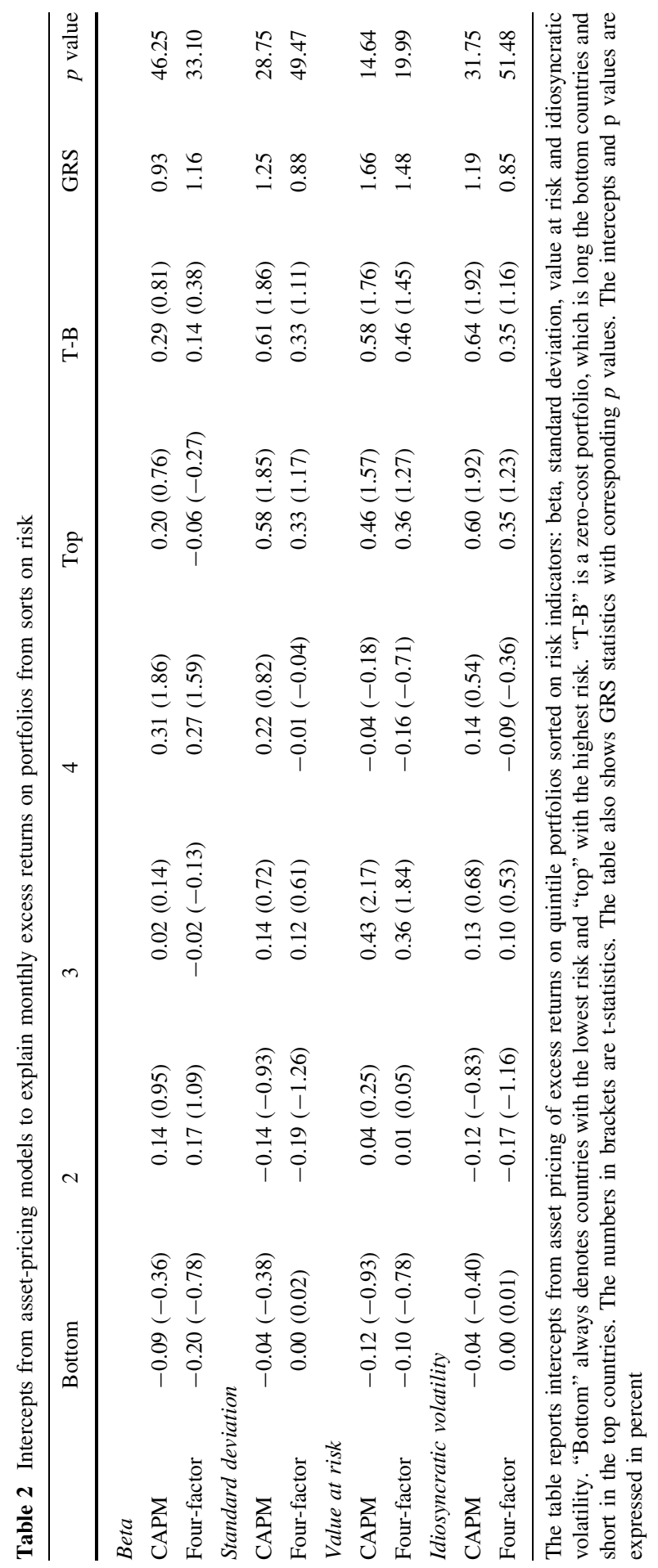


In the case of all four indictors, the risky markets always have better performance. This observation remains true even after the adjustment by crossnational value, size and momentum effects, although the abnormal returns are not significantly different from zero. Moreover, in the case of all indicators, the alphas rise (more or less steadily) with the increase in risk. However, these relationship seems to be weaker for beta and stronger for standard deviation, VaR and idiosyncratic volatility. Similarly, the abnormal returns on the zero-cost portfolios are more than two times higher in the case of standard deviation, $\mathrm{VaR}$ and idiosyncratic volatility. The monthly intercepts from CAPM on these three variables vary from 0.58 to $0.64 \%$ and are significantly different from zero at the level of $10 \%$. On the other hand, the four-factor model alphas, varying from 0.33 to $0.46 \%$, are lower and are not statistically significant. Despite the absence of significance, the mere size of intercepts is still impressive. The alphas of zero-cost portfolios based on standard deviation, value at risk and idiosyncratic volatility are levelled with the top performing country-level value, size and momentum strategies investigated by Zaremba (2015a). Finally, none of the GRS tests is rejected.

The examination of both Tables 1 and 2 helps to draw another important conclusion. Namely, it appears that the cross-sectional country-level variation in returns has a stronger correlation with the idiosyncratic risk than with the systematic risk. The expected returns appear to be determined rather by the idiosyncratic volatility than by beta, which is generally contrary to some basic concepts underlying the standard portfolio and asset pricing models.

Table 3 Excess returns on portfolios from $3 \times 3$ sorts on risk and size

\begin{tabular}{|c|c|c|c|c|c|c|c|c|}
\hline & \multicolumn{4}{|l|}{ Mean } & \multicolumn{4}{|c|}{ Standard deviation } \\
\hline & Bottom & Medium & Top & $\mathrm{T}-\mathrm{B}$ & Bottom & Medium & Top & $\mathrm{T}-\mathrm{B}$ \\
\hline \multicolumn{9}{|c|}{ Standard deviation } \\
\hline Small & 0.28 & 0.85 & 1.49 & 1.21 & 4.82 & 6.47 & 8.88 & 7.30 \\
\hline Medium & 0.63 & 0.65 & 0.98 & 0.36 & 5.13 & 6.24 & 7.86 & 5.20 \\
\hline Big & 0.23 & 0.66 & 0.68 & 0.45 & 4.42 & 6.32 & 7.58 & 4.57 \\
\hline \multicolumn{9}{|c|}{ Value at risk } \\
\hline Small & 0.46 & 1.06 & 1.86 & 1.41 & 5.00 & 6.30 & 9.02 & 7.20 \\
\hline Medium & 0.37 & 0.75 & 1.03 & 0.66 & 5.34 & 6.35 & 7.03 & 4.32 \\
\hline Big & 0.28 & 0.60 & 0.87 & 0.59 & 4.54 & 5.88 & 8.34 & 5.42 \\
\hline \multicolumn{9}{|c|}{ Idiosyncratic volatility } \\
\hline Small & 0.30 & 0.86 & 1.50 & 1.20 & 4.84 & 6.36 & 8.93 & 7.30 \\
\hline Medium & 0.61 & 0.66 & 1.00 & 0.39 & 5.13 & 6.23 & 7.82 & 5.16 \\
\hline Big & 0.23 & 0.64 & 0.73 & 0.50 & 4.42 & 6.30 & 7.63 & 4.58 \\
\hline
\end{tabular}

The table reports means and standard deviations of excess returns on nine portfolios sorted on size (market capitalization) and three risk indicators: standard deviation, value at risk and idiosyncratic volatility. "Bottom" always denotes countries with the lowest risk and "top" with the highest risk. "T-B" is a zero-cost portfolio, which is long the bottom countries and short in the top countries. The numbers are expressed in percent 


\subsection{Performance of portfolios from double sorts}

Relation between the expected returns and the underlying variables is the weakest and rather insignificant in the case of portfolios sorted on betas, thus, such portfolios have been dropped in the further research which concentrates solely on the effects related to standard deviation, value at risk and idiosyncratic volatility.

Studies on the stock-level low-volatility effect have shown little interaction between risk and size effects. Ang et al. (2006b) examined the performance of portfolios of stocks double-sorted on the idiosyncratic volatility and capitalization and found that the scale of the anomaly is relatively bigger in the case of mid-cap stocks than it is in the case of the smallest or biggest companies. The investigation of the country-level effects in this study indicates quite different behavior. Table 3 presents the performance of portfolios sorted on size and various risk indicators. The analysis of the outcomes gives two important conclusions. First, results of the country-level research basically contradict the low-risk effects from stock-level data for all the size categories. For all the variables and all the capitalization classes (small, medium, big), these are the risky stocks which have higher excess returns. Second, excess returns on risk-based zero-cost portfolios are the highest for the small markets. Their mean monthly returns vary from 1.20 to $1.41 \%$, contrary to $0.36-0.66 \%$ for big and middle markets. These results correspond with the observations of Zaremba (2015a) who claims that value and momentum effects are also stronger for small markets.

The outperformance of risky markets lacks, however, any strong confirmation through the use of the four-factor model (Table 4). The alphas on the low-risk

Table 4 Intercepts from four-factor model of portfolios from $3 \times 3$ sorts on risk and size

\begin{tabular}{|c|c|c|c|c|c|c|}
\hline & \multicolumn{3}{|l|}{ Intercept } & \multicolumn{3}{|l|}{$t$ statistic } \\
\hline & Bottom & Mid & Top & Bottom & Mid & Top \\
\hline \multicolumn{7}{|c|}{ Standard deviation } \\
\hline Small & -0.11 & 0.46 & 0.47 & $(-0.46)$ & $(1.44)$ & (1.36) \\
\hline Mid & 0.24 & 0.16 & 0.20 & $(1.14)$ & $(0.68)$ & $(0.83)$ \\
\hline Big & -0.05 & 0.17 & 0.16 & $(-1.10)$ & $(0.98)$ & $(0.61)$ \\
\hline \multicolumn{7}{|c|}{ Value at risk } \\
\hline Small & 0.00 & 0.70 & 0.81 & $(-0.01)$ & $(2.35)$ & (2.28) \\
\hline Mid & -0.06 & 0.13 & 0.41 & $(-0.30)$ & $(0.59)$ & (1.89) \\
\hline Big & -0.03 & 0.18 & 0.34 & $(-0.39)$ & (1.39) & (1.07) \\
\hline \multicolumn{7}{|c|}{ Idiosyncratic volatility } \\
\hline Small & -0.10 & 0.46 & 0.49 & $(-0.41)$ & (1.45) & (1.40) \\
\hline Mid & 0.23 & 0.16 & 0.22 & (1.07) & $(0.70)$ & $(0.92)$ \\
\hline Big & -0.06 & 0.15 & 0.21 & $(-1.14)$ & $(0.90)$ & $(0.80)$ \\
\hline
\end{tabular}

The table reports intercepts from four-factor model of nine portfolios sorted on size (market capitalization) and three risk indicators: standard deviation, value at risk and idiosyncratic volatility. "Bottom" always denotes countries with the lowest risk and "top" with the highest risk "T-B" is a zero-cost portfolio, which is long the bottom countries and short in the top countries. The intercepts are expressed in percent. The table also reports $t$ statistics 
Table 5 Summary to explain monthly excess returns on portfolios from sorts on risk and size

\begin{tabular}{lccccc}
\hline & GRS & $p$ value & $|\alpha|$ & $\mathrm{R}^{2}$ & $\mathrm{~s}(\alpha)$ \\
\hline Standard deviation & & & & & \\
CAPM & 1.12 & 35.35 & 0.36 & 69.22 & 0.32 \\
$\begin{array}{l}\text { Four-factor model } \\
\text { Value atrisk }\end{array}$ & 0.86 & 56.05 & 0.22 & 75.39 & 0.19 \\
CAPM & & & & & \\
Four-factor model & 1.04 & 3.79 & 0.44 & 69.42 & 0.43 \\
$\begin{array}{l}\text { Idiosyncraticvolatility } \\
\text { CAPM }\end{array}$ & 1.94 & 4.92 & 0.30 & 75.65 & 0.32 \\
Four-factor model & 0.86 & 36.38 & 0.37 & 69.25 & 0.32 \\
\hline
\end{tabular}

The table reports regression results for the CAPM and four-factor models. The models aim to explain the excess returns of nine portfolios formed on risk indicators (standard deviation, value at risk and idiosyncratic volatility) and size (market capitalization). GRS is the Gibbons et al. (1989) statistic, $|\alpha|$ is the average absolute intercept, $R^{2}$ is the average $R^{2}$ and $s(\alpha)$ is the standard deviation of the intercepts. The $\mathrm{p}$ values, intercepts, $\mathrm{R}^{2}$ and standard deviations of the intercepts are expressed in percent

portfolios are still predominantly lower (or even frequently negative) than alphas on the high-risk portfolios. Furthermore, the anomaly is still stronger for small markets, although the asset-pricing model takes into account the country-level SMB factor. Alas, hardly any of these abnormal returns are statistically significant. The only exception are returns on small and medium markets with low value at risk. The monthly alpha on the portfolio of the smallest markets with the lowest value at risk is $0.81 \%$ and it is significantly different from zero.

Table 5 summarizes the results of the performance analysis of portfolios sorted on risk and size. Basically, the GRS tests are not rejected in the case of sorts on standard deviation and idiosyncratic volatility, but are rejected in the case of sorts on value at risk. In other words, it appears that the efficient frontier of a global investor can be significantly augmented only through the application of an additional sort on VaR to the country-level size strategy. ${ }^{4}$ In this case, the mean monthly alpha for the CAPM model is $0.44 \%$ and the model explains over $69 \%$ of variations in stock returns. In the case of the four-factor model, the mean intercept falls to $0.30 \%$ and $\mathrm{R}^{2}$ increases to almost $76 \%$. However, the GRS test is still rejected. To compare, none of the strategies from double sorts on size, value and momentum examined by Zaremba (2015a) rejected the GRS tests so significantly.

The observed performance of the VaR-based portfolios, which is superior to other variables, reveals some similarities to the stock-level findings of Bali and Cakici (2004). They proved that VaR may explain the cross-sectional variation in stock returns much better than any other risk-related variables, such as beta or total volatility.

Apart from the stock market capitalization, the risk effect seems to interact also with the country-level value effect. The results depicted in Table 6 seem to suggest that the risk-return relationship is stronger in the case of the value markets than it is

\footnotetext{
${ }^{4}$ The performed asset pricing tests can be interpreted as tests of mean-variance spanning. For further details, see de Roon and Nijman (2001) and Kan and Zhou (2008).
} 
Table 6 Excess returns on portfolios from $3 \times 3$ sorts on risk and B/M

\begin{tabular}{|c|c|c|c|c|c|c|c|c|}
\hline & \multicolumn{4}{|l|}{ Mean } & \multicolumn{4}{|c|}{ Standard deviation } \\
\hline & Bottom & Medium & Top & T-B & Bottom & Medium & Top & $\mathrm{T}-\mathrm{B}$ \\
\hline \multicolumn{9}{|c|}{ Standard deviation } \\
\hline Low B/M & 0.31 & 0.56 & 0.38 & 0.07 & 4.52 & 6.33 & 7.67 & 5.16 \\
\hline Medium B/M & 0.41 & 0.65 & 0.83 & 0.42 & 5.14 & 6.21 & 7.66 & 4.87 \\
\hline High $\mathrm{B} / \mathrm{M}$ & 0.13 & 1.04 & 1.03 & 0.89 & 6.46 & 7.15 & 8.63 & 7.23 \\
\hline \multicolumn{9}{|l|}{ Value at risk } \\
\hline Low B/M & 0.23 & 0.80 & 0.46 & 0.23 & 4.61 & 6.24 & 7.81 & 5.01 \\
\hline Medium B/M & 0.42 & 0.92 & 0.98 & 0.56 & 5.49 & 6.34 & 7.28 & 4.39 \\
\hline High B/M & 0.27 & 1.03 & 1.51 & 1.24 & 6.22 & 7.34 & 9.36 & 8.25 \\
\hline \multicolumn{9}{|c|}{ Idiosyncratic volatility } \\
\hline Low B/M & 0.31 & 0.58 & 0.43 & 0.13 & 4.52 & 6.34 & 7.67 & 5.19 \\
\hline Medium B/M & 0.39 & 0.67 & 0.82 & 0.44 & 5.14 & 6.22 & 7.65 & 4.87 \\
\hline High $\mathrm{B} / \mathrm{M}$ & 0.12 & 0.95 & 1.15 & 1.03 & 6.43 & 7.12 & 8.69 & 7.32 \\
\hline
\end{tabular}

The table reports means and standard deviations of excess returns on nine portfolios sorted on book-tomarket ratio and three risk indicators: standard deviation, value at risk and idiosyncratic volatility. "Bottom" always denotes countries with the lowest risk and "top" with the highest risk. "T-B" is a zerocost portfolio, which is long the bottom countries and short in the top countries. The numbers are expressed in percent

Table 7 Intercepts from fourfactor model of portfolios from $3 \times 3$ sorts on risk and $\mathrm{B} / \mathrm{M}$

The table reports intercepts from four-factor model of nine portfolios sorted on book-tomarket ratio and three risk indicators: standard deviation, value at risk and idiosyncratic. "Bottom" always denotes countries with the risk and "top" with the highest risk. The intercepts are expressed in percent. The table also reports $t$ statistics

\begin{tabular}{|c|c|c|c|c|c|c|}
\hline & \multicolumn{3}{|l|}{ Intercept } & \multicolumn{3}{|l|}{$t$ statistic } \\
\hline & Bottom & Mid & Top & Bottom & Mid & Top \\
\hline \multicolumn{7}{|c|}{ Standard deviation } \\
\hline Low B/M & 0.05 & 0.17 & 0.06 & $(0.59)$ & $(0.73)$ & $(0.19)$ \\
\hline Mid B/M & 0.02 & 0.18 & 0.22 & $(0.14)$ & $(0.88)$ & $(0.74)$ \\
\hline High B/M & -0.32 & 0.46 & 0.10 & $(-0.97)$ & $(1.89)$ & $(0.34)$ \\
\hline \multicolumn{7}{|c|}{ Value at risk } \\
\hline Low B/M & -0.01 & 0.39 & 0.12 & $(-0.08)$ & (1.93) & $(0.41)$ \\
\hline Mid B/M & -0.02 & 0.55 & 0.38 & $(-0.09)$ & $(2.12)$ & $(1.35)$ \\
\hline High B/M & -0.16 & 0.41 & 0.33 & $(-0.48)$ & (1.63) & (1.04) \\
\hline \multicolumn{7}{|c|}{ Idiosyncratic volatility } \\
\hline Low B/M & 0.05 & 0.19 & 0.12 & $(0.59)$ & $(0.83)$ & $(0.41)$ \\
\hline Mid B/M & 0.00 & 0.20 & 0.22 & $(0.01)$ & $(0.97)$ & $(0.73)$ \\
\hline High B/M & -0.33 & 0.38 & 0.23 & $(-0.99)$ & $(1.53)$ & $(0.76)$ \\
\hline
\end{tabular}

in the case of the growth countries. This observation appears to be valid for all three examined risk variables: standard deviation, value at risk and idiosyncratic volatility. The mean monthly excess returns on long/short portfolios are between 0.07 and $0.23 \%$ for the low $\mathrm{B} / \mathrm{M}$ countries and vary from 0.89 to $1.24 \%$ for the high $\mathrm{B} / \mathrm{M}$ countries. Again, the most impressive performance is yielded by sorts on value at risk. The top $\mathrm{B} / \mathrm{M}$ and $\mathrm{VaR}$ portfolio has the average monthly excess return 
Table 8 Summary to explain monthly excess returns on portfolios from sorts on risk and B/M

\begin{tabular}{lccccc}
\hline & GRS & $p$ value & $|\alpha|$ & $\mathrm{R}^{2}$ & $\mathrm{~s}(\alpha)$ \\
\hline Standard deviation & & & & & \\
CAPM & 1.00 & 44.33 & 0.25 & 73.72 & 0.27 \\
Four-factor model & 0.66 & 74.21 & 0.18 & 76.59 & 0.21 \\
Value at risk & & & & & \\
CAPM & 1.68 & 9.68 & 0.36 & 71.25 & 0.37 \\
Four-factor model & 1.27 & 25.80 & 0.26 & 75.41 & 0.24 \\
$\begin{array}{l}\text { Idiosyncratic volatility } \\
\text { CAPM }\end{array}$ & 0.95 & 48.27 & 0.25 & 73.52 & 0.27 \\
Four-factor model & 0.61 & 78.42 & 0.19 & 76.33 & 0.20 \\
\hline
\end{tabular}

The table reports regression results for the CAPM and four-factor models. The models aim to explain the excess returns of nine portfolios formed on risk indicators (standard deviation, value at risk and idiosyncratic) and book-to-market ratio. GRS is the Gibbons et al. (1989) statistic, $|\alpha|$ is the average absolute intercept, $\mathrm{R}^{2}$ is the average $\mathrm{R}^{2}$ and $\mathrm{s}(\alpha)$ is the standard deviation of the intercepts. The $p$ values, intercepts, $\mathrm{R}^{2}$ and standard deviations of the intercepts are expressed in percent

of $1.51 \%$. However, it is also considerably risky-the monthly standard deviation of excess returns is as high as $9.36 \%$.

Similarly as it is in the case of double-sorts on size and risk, the most abnormal returns on country portfolios from sorts $\mathrm{B} / \mathrm{M}$ and risk lack any statistical significance (Table 7). Although intercepts from the four-factor model follow the pattern observable in excess returns (larger alphas on volatile stock among small markets) to a large extent, they are hardly statistically significant. In fact, only single VaR-based portfolios have alphas significantly different from zero.

Table 8 presents the summary which proves the absence of any statistical significance. The GRS test statistics for sorts on standard deviation and idiosyncratic volatility are very low and the corresponding $p$ values exceed $40 \%$. The exception is the value at risk. In this case, the GRS test is rejected for the CAPM model. The corresponding average absolute intercept is $0.36 \%$ and $\mathrm{R}^{2}$ equals $71.25 \%$. Nevertheless, if country-level value, size and momentum effects are taken into account, the GRS test is no longer rejected. The average absolute intercept for the four-factor model declines to $0.26 \%$ and $\mathrm{R}^{2}$ rises to more than $75 \%$. It appears that the performance of the value strategy is improved when the additional sorting on $\mathrm{VaR}$ is applied, but the abnormal returns can be, to a large extent, explained by the cross-national value, size and momentum effects.

\section{Conclusions}

The calculation performed in this study shows no parallels between the country-level and the stock-level low-risk anomalies. Risky stock markets have higher returns than safe markets. The zero-cost portfolios, which are long for countries with high standard deviation, VaR or idiosyncratic volatility, are characterized by positive abnormal returns which are to partially explained by the cross-national value, size and momentum effects. Moreover, the available evidence suggests that country-level 
return patterns are determined rather by the idiosyncratic than by the systematic risk (measured with market beta). Furthermore, additional sorting on VaR may significantly improve the performance of size and value strategies at the country level.

In the resulting findings may be a source of valuable lessons for investors, asset managers and fund pickers, First of all, it seems that country-level standard deviation, idiosyncratic volatility and particularly VaR may serve as the basis for the development of valuable tools for global investors which invest in passive stock market products, such as ETFs and index funds. Second, the discussed factor-based strategies may also be implemented by traditional investment managers. Taking into account the growing integration of international stock markets and the declining diversification benefits, it seems sensible to take into account the country-level factor premiums in the strategic asset allocation, and avoid any delays regarding the consideration of factor premiums within the investment process.

It should be stressed that the results of this research have several limitations of potentially high relevance. First of all, the research sample is relatively small (considering pure numbers), so it may lead to the small-sample bias. Obviously, it is impossible to markedly increase the sample. Second, the research period covers also the years of global financial crisis which may distort the findings to the extent which is difficult to assess. In other words, the outcomes may be period-specific in some way. Finally, the study does not take into account any transactions costs, liquidity constraints and impacts of country-specific taxation.

The country-level phenomena presented in this study seems to contradict the stock-level low-risk return patterns. We hypothesize that these observations could be explained with the economic hypotheses which are already discussed in the academic literature. First of all, it is necessary to divide the observed patterns into two separate groups depending on the relationship between returns and betas (systematic risk) and the relationship between returns and idiosyncratic volatility. Considering the first phenomenon, the current state of the debate on the low-beta anomaly indicates that it could be explained with two basis tools: benchmarks for institutional investors discouraging them from investing in low-beta assets which are not included in or have small representation in the benchmark portfolios (Baker et al. 2011), and limitations to arbitrage, i.e. particularly leverage and short-selling constraints that, in turn, prevent investors from exploiting the mispricing phenomenon (Frazzini and Pedersen 2014). Both above-mentioned issues are also observable at the country-level, especially in the case of small markets that are marginally represented in global indices and cannot be easily accessed with ETFs or futures. In consequence, the return-beta relationship is blurred and do not follow the expectations of the CAPM, although the effect is not as strong as it is at the stock level. With regard to the return-idiosyncratic volatility relationship, it could be explained with the theories according to which, under conditions of underdiversification, the idiosyncratic risk should be positively correlated with the expected returns in the cross-section analysis (Levy 1978; Merton 1987; Malkiel and $\mathrm{Xu} 2004$ ). The question whether these theories and models are sufficient to fully explain the patterns documented in this study remains open for future studies.

Further research on the issues discussed in this paper could be pursued in several directions. First, this research constituted the paradigm for any future studies on 
different return patterns related to the price risk measures, which were discovered in stock-level data, for example negative risk (Ang et al. 2006a) or skewness (Harvey and Siddique 2002) effects. Second, one of the drawbacks of the performed computations is the non-consideration of transaction costs, liquidity and capital mobility constraints, as well as taxation issues. These aspects should be treated more carefully in further studies, especially that they may serve as the partial explanation of the examined effects. Third, the impact of certain market-specific issues, such as the level of development, integration, investors' structure or openness, should be examined. Finally, the study revealed that the impact of volatility on returns may vary across size and value classes. Future studies could extend this investigation into different dimensions, such as profitability or credit risk (Zaremba 2015b). Particularly, there are a few anomaly variations that appear to partly explain the low-risk anomaly at the stock-level: liquidity (Bali and Cakici 2008), past maximum returns (Bali et al. 2011), short-term reversal (Huang et al. 2010), and skewness (Schneider et al. 2015). Examination of portfolios from double-sorts on these metrics and volatility could bring some additional insights into the nature of the low-risk anomaly.

Acknowledgments This study is a part of the project no. 2014/15/D/HS4/01235 financed by the National Science Centre of Poland.

Open Access This article is distributed under the terms of the Creative Commons Attribution 4.0 International License (http://creativecommons.org/licenses/by/4.0/), which permits unrestricted use, distribution, and reproduction in any medium, provided you give appropriate credit to the original author(s) and the source, provide a link to the Creative Commons license, and indicate if changes were made.

\section{Appendix: Research sample}

See Table 9.

Table 9 The table presents a list of countries investigated in this research along with corresponding index providers

\begin{tabular}{lllllllll}
\hline No. & Country & $\begin{array}{l}\text { Index } \\
\text { provider }\end{array}$ & No. & Country & $\begin{array}{l}\text { Index } \\
\text { provider }\end{array}$ & No. & Country & $\begin{array}{l}\text { Index } \\
\text { provider }\end{array}$ \\
\hline 1 & Argentina & MSCI & 27 & Indonesia & MSCI & 53 & Poland & MSCI \\
2 & Australia & MSCI & 28 & Ireland & MSCI & 54 & Portugal & MSCI \\
3 & Austria & MSCI & 29 & Israel & MSCI & 55 & Qatar & MSCI \\
4 & Bahrain & MSCI & 30 & Italy & MSCI & 56 & Romania & MSCI \\
5 & Bangladesh & MSCI & 31 & Japan & MSCI & 57 & Russia & MSCI \\
6 & Belgium & MSCI & 32 & Jordan & MSCI & 58 & Serbia & MSCI \\
7 & Brazil & MSCI & 33 & Kazakhstan & MSCI & 59 & Saudi Arabia & MSCI \\
8 & Bulgaria & MSCI & 34 & Kenya & MSCI & 60 & Singapore & MSCI \\
9 & Canada & MSCI & 35 & Kuwait & MSCI & 61 & Slovenia & MSCI \\
10 & Chile & MSCI & 36 & Latvia & STOXX & 62 & SouthAfrica & MSCI \\
11 & China & MSCI & 37 & Lebanon & MSCI & 63 & South Korea & MSCI \\
\hline
\end{tabular}


Table 9 continued

\begin{tabular}{|c|c|c|c|c|c|c|c|c|}
\hline No. & Country & $\begin{array}{l}\text { Index } \\
\text { provider }\end{array}$ & No. & Country & $\begin{array}{l}\text { Index } \\
\text { provider }\end{array}$ & No. & Country & $\begin{array}{l}\text { Index } \\
\text { provider }\end{array}$ \\
\hline 12 & Colombia & MSCI & 38 & Lithuania & MSCI & 64 & Spain & MSCI \\
\hline 13 & Croatia & MSCI & 39 & Luxemburg & STOXX & 65 & Sri Lanka & MSCI \\
\hline 14 & Cyprus & $\begin{array}{l}\text { Dow } \\
\text { Jones }\end{array}$ & 40 & Malaysia & MSCI & 66 & Sweden & MSCI \\
\hline 15 & $\begin{array}{l}\text { Czech } \\
\text { Republic }\end{array}$ & MSCI & 41 & Malta & $\begin{array}{l}\text { Dow } \\
\text { Jones }\end{array}$ & 67 & Switzerland & MSCI \\
\hline 16 & Denmark & MSCI & 42 & Mexico & MSCI & 68 & Taiwan & MSCI \\
\hline 17 & Egypt & MSCI & 43 & Morocco & MSCI & 69 & Thailand & MSCI \\
\hline 18 & Estonia & MSCI & 44 & Mauritius & MSCI & 70 & $\begin{array}{c}\text { Trinidad and } \\
\text { Tobago }\end{array}$ & MSCI \\
\hline 19 & Finland & MSCI & 45 & Netherlands & MSCI & 71 & Tunisia & MSCI \\
\hline 20 & France & MSCI & 46 & $\begin{array}{l}\text { New } \\
\quad \text { Zealand }\end{array}$ & MSCI & 72 & Turkey & MSCI \\
\hline 21 & Germany & MSCI & 47 & Nigeria & MSCI & 73 & Ukraine & MSCI \\
\hline 22 & Greece & MSCI & 48 & Norway & MSCI & 74 & $\begin{array}{c}\text { United Arab } \\
\text { Emirates }\end{array}$ & MSCI \\
\hline 23 & Hong Kong & MSCI & 49 & Oman & MSCI & 75 & $\begin{array}{l}\text { United } \\
\quad \text { Kingdom }\end{array}$ & MSCI \\
\hline 24 & Hungary & MSCI & 50 & Pakistan & MSCI & 76 & USA & MSCI \\
\hline 25 & Iceland & $\begin{array}{l}\text { Dow } \\
\text { Jones }\end{array}$ & 51 & Peru & MSCI & 77 & Venezuela & MSCI \\
\hline 26 & India & MSCI & 52 & Philippines & MSCI & 78 & Vietnam & MSCI \\
\hline
\end{tabular}

\section{References}

Ang, A. (2014). Asset management. A systematic approach to factor investing. New York: Oxford University Press.

Ang, A., Chen, J., \& Xing, Y. (2006a). Downside risk. Review of Financial Studies, 19, 1191-1239.

Ang, A., Chen, J., \& Xing, Y. (2006b). The cross-section of volatility and expected returns. Journal of Finance, 61, 259-299.

Ang, A., Hodrick, R., Xing, Y., \& Zhang, X. (2008). High idiosyncratic volatility and low returns: international and further U.S. evidence. Journal of Financial Economics, 91, 1-23.

Angelidis, T., \& Tessaromatis, N. (2014). Global style portfolios based on country indices, MPRA Paper No. 53094. Available from: http://mpra.ub.uni-muenchen.de/53094. Accessed 9 Dec 2014.

Asness, C., Liew, J., \& Stevens, R. L. (1997). Parallels between the cross-sectional predictability of stock and country returns. Journal of Portfolio Management, 6, 79-86.

Asness, C. S., Moskowitz, T. J., \& Pedersen, L. H. (2013). Value and momentum everywhere. Journal of Finance, 68(3), 929-985.

Authers, J. (2010). The fearful rise of markets: global bubbles, synchronized meltdowns, and how to prevent them in the future. London: FT Press.

Baker, M., Bradley, B., \& Wurgler, J. (2011). Benchmarks as limits to arbitrage: understanding the lowvolatility anomaly. Financial Analyst Journal, 67(1), 40-54.

Baker, R., \& Haugen, N. (1991). The efficient market inefficiency of capitalization-weighted stock portfolios. Journal of Portfolio Management, 17(1), 35-40.

Baker, N.L., \& Haugen, R.A. (2012). Low risk stocks outperform within all observable markets of the world, working paper, available at SSRN: http://dx.doi.org/10.2139/ssrn.2055431. Accessed 9 Dec 2014. 
Bali, T. G., \& Cakici, N. (2004). Value at risk and expected stock returns. Financial Analyst Journal, $60(2), 57-73$.

Bali, T. G., \& Cakici, N. (2008). Idiosyncratic volatility and the cross section of expected returns. Journal of Financial Economics, 99, 427-446.

Bali, C., Cakici, N., \& Fabozzi, F. (2013). Book-to-market and the cross-section of expected stock returns in international stock markets. Journal of Portfolio Management, 39, 101-115.

Bali, T. G., Cakici, N., \& Whitelaw, R. F. (2011). Maxing out: stocks as lotteries and the cross section of expected returns. Journal of Financial and Quantitative Analysis, 43, 29-58.

Balvers, R., \& Wu, Y. (2006). Momentum and mean reversion across national equity markets. Journal of Empirical Finance, 13, 24-48.

Bekaert, G., \& Harvey, C. R. (2000). Foreign speculators and emerging equity markets. Journal of Finance, 55, 565-613.

Bekaert, G., Harvey, C., \& Lundblad, C. (2007). Liquidity and expected returns: lessons from emerging markets. Review of Financial Studies, 20, 1783-1831.

Bhojraj, S., \& Swaminathan, B. (2006). Macromomentum: returns predictability in international equity indices. Journal of Business, 79(1), 429-451.

Black, F. (1972). Capital market equilibrium with restricted borrowing. Journal of Business, 45(3), 444-455.

Black, F., Jensen, M. C., \& Scholes, M. S. (1972). The capital asset pricing model: some empirical tests. In M. C. Jensen (Ed.), Studies in the theory of capital markets (pp. 79-121). New York: Praeger Publishers.

Blitz, D. C., \& van Vliet, P. (2007). The volatility effect: lower risk without lower return. Journal of Portfolio Management, 34(1), 102-113.

Blitz, D. C., \& van Vliet, P. (2008). Global tactical cross-asset allocation: applying value and momentum across asset classes. Journal of Portfolio Management, 35(1), 23-38.

Blitz, D. C., \& de Groot, W. (2014). Strategic allocation to commodity factor premiums. Journal of Alternative Investments, 17(2), 103-115.

Blitz, D. C., Pang, J., \& van Vliet, P. (2013). The volatility effect in emerging markets. Emerging Markets Review, 16, 31-45.

Blume, M. E. (1970). Portfolio theory: a step towards its practical application. Journal of Business, 43(2), $152-174$.

Blume, M. E., \& Friend, I. (1973). A new look at the capital asset pricing model. Journal of Finance, 28(1), 19-34.

Boyer, B., Mitton, T., \& Vorkink, K. (2010). Expected idiosyncratic skewness. Review of Financial Studies, 23, 169-202.

Brown, A., Du, D. Y., Rhee, S. G., \& Zhang, L. (2008). The returns to value and momentum in Asian markets. Emerging Markets Review, 9, 79-88.

Cao, J., \& Han, B. (2013). Cross section of option returns and idiosyncratic volatility. Journal of Financial Economics, 108, 231-249.

Carhart, M. M. (1997). On persistence in mutual fund performance. Journal of Finance, 52, 57-82.

Chan, L., Karceski, J., \& Lakonishok, J. (1999). On portfolio optimization: forecasting covariances and choosing the risk model. Review of Financial Studies, 12, 937-974.

Chen, D. H., Chen, C. D., \& Wu, S. C. (2014). VaR and the cross-section of expected stock returns: an emerging market evidence. Journal of Business Economics and Management, 15(3), 441-459.

Clarke, R., de Silva, H., \& Thorley, S. (2006). Minimum-variance portfolios in the US equity market. Journal of Portfolio Management, 33(1), 10-24.

de Moor, L., \& Sercu, P. (2013). The smallest firm effect: an international study. Journal of International Money and Finance, 32, 129-155.

de Roon, F. A., \& Nijman, Th E. (2001). Testing for mean-variance spanning: a survey. Journal of Empirical Finance, 8, 111-155.

Desrosiers, S., L'Her, J.-F., \& Plante, J.-F. (2004). Style management in equity country allocation. Financial Analyst Journal, 60(6), 40-54.

Dornbusch, R., Park, Y. C., \& Claessens, S. (2000). Contagion: understanding how it spreads. World Bank Research Observer, 15(2), 177-197.

Erb, C. B., \& Harvey, C. R. (2006). The strategic and tactical value of commodity futures. Financial Analysts Journal, 62, 69-97. 
EY (2014). Global ETF Survey. A new era of growth and innovation, available from: http://www.ey.com/ Publication/vwLUAssets/EY_-_Global_ETF_Survey_2014/\$FILE/EY-Global-ETF-SurveyJanuary-2014.pdf. Accessed 8 Dec 2014.

Fama, E. F., \& French, K. R. (1992). The cross-section of expected stock returns. Journal of Finance, 47(2), 427-465.

Fama, E. F., \& French, K. R. (1993). Common risk factors in the returns on stocks and bonds. Journal of Financial Economics, 33, 3-56.

Fama, E. F., \& MacBeth, J. D. (1973). Risk, return and equilibrium: empirical tests. Journal of Political Economy, 81(3), 607-636.

Frazzini, A., Kabiller, D., Pedersen, L.H. (2013). Buffett's Alpha, NBER Working Paper No. w19681, available at SSRN: http://ssrn.com/abstract=2360949. Accessed 10 Dec 2014.

Frazzini, A., \& Pedersen, L. H. (2014). Betting against beta. Journal of Financial Economics, 111, 1-25.

Friend, I., \& Blume, M. (1970). Measurement of portfolio performance under uncertainty. American Economic Review, 60, 607-636.

Fu, F. (2009). Idiosyncratic risk and the cross-section of expected stock returns. Journal of Financial Economics, 91, 24-37.

Gibbons, M. R., Ross, S. A., \& Shanken, J. (1989). A test of the efficiency of a given portfolio. Econometrica, 57, 1121-1152.

Goetzman, W.N., \& Kumar, A. (2008). Equity portfolio diversification. Review of Finance, 12(3), 433-463.

Han, Y., \& Lesmond, D. (2011). Liquidity biases and the pricing of cross-sectional idiosyncratic volatility. Review of Financial Studies, 24, 1590-1629.

Harvey, C. R., \& Siddique, A. (2002). Conditional skewness in asset pricing tests. Journal of Finance, 55(3), 1263-1295.

Haugen, R. A., \& Heins, A. J. (1975). Risk and the rate of return on financial assets: some old wine in new bottles. Journal of Financial and Quantitative Analysis, 10(5), 775-784.

Hester, W. (2013). Fed Leaves Punchbowl, Takes Away Free Lunch (of International Diversification), Hausman Funds Investment Research Insight, available from: http://www.hussmanfunds.com/rsi/ intldiversification.htm. Accessed 8 Dec 2014.

Hou, K., \& Loh, R. (2014). Have we solved the idiosyncratic volatility puzzle? Charles A. Dice Center Working Paper No. 2012-28, available at SSRN: http://dx.doi.org/10.2139/ssrn.2190976. Accessed 10 Oct 2014.

Huang, V., Liu, Q., Rhee, S. G., \& Zhang, L. (2010). Return reversals, idiosyncratic risk, and expected returns. Review of Financial Studies, 23(1), 147-168.

Ilmanen, A. (2012). Do financial markets reward buying or selling insurance and lottery ticket? Financial Analyst Journal, 69, 26-36.

Investment Company Institute (2014). Exchange-traded funds: September 2014. ICI Research Statistics, available from: http://www.ici.org/research/stats/etf/etfs_09_14. Accessed 8 Nov 2014.

Jagannathan, R., \& Ma, T. (2003). Risk reduction in large portfolios: Why imposing the wrong constrains helps. Journal of Finance, 58(4), 1651-1684.

Jensen, M. C., Black, F., \& Scholes, M. S. (1972). The capital asset pricing model: some empirical tests. In M. C. Jensen (Ed.), Studies in the theory of Capital Markets. New York: Praeger Publishers.

Kan, R., \& Zhou, G. (2008). Tests of mean-variance spanning, OLIN Working Paper No. 99-05, available from URL: http://dx.doi.org/10.2139/ssrn.231522. Accessed 2 Dec 2014.

Keppler, M., \& Encinosa, P. (2011). The small-country effect revisited. Journal of Investing, 20(4), 99-103.

Keppler, M., \& Traub, H. (1993). The small-country effect: small markets beat large markets. Journal of Investing, 2(3), 17-24.

Kim, D. (2012). Value premium across countries. Journal of Portfolio Management, 38(4), $75-86$.

Le, C., \& David, D. (2014). Asset price volatility and financial contagion: analysis using the MS-VAR framework. Eurasian Economic Review, 4(2), 133-162.

Levy, H. (1978). Equilibrium in an imperfect market: a constraint on the number of securities in the portfolio. American Economic Review, 68, 643-658.

Liew, J., \& Vassalou, M. (2000). Can book-to-market, size and momentum be risk factors that predict economic growth? Journal of Financial Economics, 57, 221-245.

Lintner, J. (1965). The valuation of risk assets and the selection of risky investments in stock portfolios and capital budget. Review of Economics and Statistics, 47, 13-37. 
Liu, M., Liu, Q., \& Ma, T. (2011). The 52-week high momentum strategy in international stock markets. Journal of International Money and Finance, 30, 180-204.

Macedo, R. (1995). Country-selection style. In J. Lederman \& R. A. Klein (Eds.), Equity style management: evaluating and selecting investment styles. Burr Ridge: Irwin Professional Publishing.

Malkiel, B., \& Xu, Y. (2004). Idiosyncratic risk and security returns, working paper, available at SSRN: http://dx.doi.org/10.2139/ssrn.255303. Accessed 10 Dec 2014.

Merton, R. (1987). A simple model of capital market equilibrium with incomplete information. Journal of Finance, 42, 483-510.

Miller, M. H., \& Scholes, M. (1972). Rates of return in relation to risk: a reexamination of some recent findings. In M. C. Jensen (Ed.), Studies in the Theory of Capital Markets. New York: Praeger.

MSCI (2014a). MSCI Global Market Accessibility Review, available from: http://www.msci.com/ resources/products/indexes/global_equity_indexes/gimi/stdindex/MSCI_Global_Market_ Accessibiliy_Review_June2014.pdf. Accessed 1 Nov 2014.

MSCI (2014b). MSCI global investable market indexes methodology, available from: http://www.msci. com/eqb/methodology/meth_docs/MSCI_Aug14_GIMIMethod.pdf. Accessed 1 Nov 2014.

Novy-Marx, R. (2013). The other side of value: the gross profitability premium. Journal of Financial Economics, 108(1), 1-28.

Quinn, D. P., \& Voth, H. J. (2008). Century of stock market correlations and international financial openness. American Economic Review, 98, 529-534.

Richards, A. (1997). Winner-loser reversals in national stock market indices: can they be explained? Journal of Finance, 52, 2129-2144.

Schneider, P., Wagner, C., \& Zechner, J. (2015). Low risk anomalies? Working paper available at SSRN: http://ssrn.com/abstract=2593519 or http://dx.doi.org/10.2139/ssrn.2593519. Accessed 10 Aug 2015.

Scott, H.S. (2014). Interconnectedness and Contagion-Financial Panics and the Crisis of 2008, working paper, available at SSRN: http://ssrn.com/abstract=2178475 or http://dx.doi.org/10.2139/ssrn. 2178475. Accessed 31 Aug 2015.

Sharpe, W. F. (1964). Capital asset pricing: a theory of market equilibrium under conditions of risk. Journal of Finance, 19, 425-441.

Tanai, Y., \& Lin, K.-P. (2013). Mongolian and world equity markets: volatilities and correlations. Eurasian Economic Review, 3(2), 136-164.

West, S. M., \& Tinic, R. R. (1986). Risk, return and equilibrium: a revisit. Journal of Political Economy, 94, 126-147.

Willenbrock, S. (2011). Diversification return, portfolio rebalancing, and the commodity return puzzle. Financial Analyst Journal, 67(4), 42-49.

Zaremba, A. (2015a). Country selection strategies based on value, size and momentum. Investment Analyst Journal, 44(3), 171-198.

Zaremba, A. (2015b). Country selection strategies based on quality, Managerial Finance, forthcoming, working paper available at SSRN: http://ssrn.com/abstract=2536807 or http://dx.doi.org/10.2139/ ssrn.2536807. Accessed 10 Aug 2015. 